\title{
Comportamento da castanha-do-brasil (Bertholletia excelsa) e da cupiúba (Goupia glabra) em sistema agrosilvicultural na região da Confiança, Cantá - Roraima $^{(1)}$
}

\author{
Liane Marise Moreira FERREIRA ${ }^{1}$, Helio TONINI² \\ RESUMO \\ O presente trabalho objetivou estudar o desempenho das espécies castanha-do-brasil (Bertholetia excelsa) e cupiúba (Goupia \\ glabra) e o ajuste de uma função de crescimento e uma equação para estimar o diâmetro de copa em um modelo de sistema \\ agroflorestal - SAF implantado em 1995 no Campo Experimental Confiança, Cantá, Estado de Roraima. Foram medidas \\ 71 árvores de castanheira e 50 de cupiúbas totalizando 121 árvores, sendo tomados o CAP (circunferência a 1,30 m do \\ solo), altura total, altura de inserçáo da copa, diâmetro da copa e dados qualitativos como sobrevivência, qualidade do fuste, \\ bifurcaçóes e aspectos fitossanitários como doenças ou pragas. Das 71 árvores de castanheira avaliadas 20 (27,8\%) produziram \\ frutos. A cupiúba apresentou alta porcentagem de indivíduos com bifurcação (cerca de 87,5\%). A análise estatística indicou a \\ função de Backman como a de melhor ajuste para as espécies observadas e com base nas equaçóes construídas para estimar o \\ diâmetro da copa em função do DAP pode-se fazer inferências sobre o espaço vital necessário para atingir uma determinada \\ dimensão. Ambas as espécies apresentaram potencial silvicultural para recuperação de áreas alteradas em sistemas agroflorestais \\ ou plantios homogêneos.
}

PALAVRAS-CHAVE: Bertholletia excelsa, goupia glabra, sistemas agroflorestais, Roraima.

\section{Behavior of castanha-do-brasil (Bertholletia excelsa) and cupiúba (Goupia glabra) in an agrosilvicultural system in Confiança region, Cantá - Roraima State ${ }^{(1)}$}

\begin{abstract}
The aim of this present work was to study the behavior of castanha-do-brasil (Bertholletia excelsa) and cupiúba (Goupia glabra) and also set a growing function and an equation for estimating the crown diameter in an agroforestry system model, installed in Confiança Experimental Station, Cantá, Roraima, Brazil, in 1995. We measured quantitative data, such as diameter basal height, total height, crown insertion height, crown diameter and qualitative data like survival, bole quality and phytosanitary aspects such as disease or pests. We analyzed the silvicultural behavior and estimated equation at the crown diameter in function of $\mathrm{DBH}$, and adjusted a growing function for the cupiuba and castanha-do-brasil. Of the 71 castanha-do-brasil trees analyzed $20(27,8 \%)$ producing fruits. The cupiúba showed high individual percentage of bifurcation (around 87,5\%). The statistical analyses indicated the Backman function as the best adjusted for the observed species; and based on the equations for estimating crown diameter in function of $\mathrm{DBH}$, we could make inferences about the necessary vital space for reaching determinated dimension. Both species have silvicultural potential for restored areas in agroforestry systems or homogeneous plantations.
\end{abstract}

KEYWORDS: Bertholletia excelsa, goupia glabra, agroforestry system, Roraima.

\footnotetext{
1 Empresa Brasileira de Pesquisa Agropecuária-Roraima. E-mail: liane@cpafrr.embrapa.br

${ }^{2}$ Empresa Brasileira de Pesquisa Agropecuária-Roraima. E-mail: helio@cpafrr.embrapa.br
} 


\section{INTRODUÇÃO}

A constante da exploração em áreas de florestas primárias segue métodos considerados muito agressivos e prejudiciais ao seu melhor desenvolvimento. E, cada vez ampliando seu espaço como forma alternativa de uso do solo os estudos com sistemas agroflorestais (SAFs) procuram fornecer uma resposta adequada para tal fim. Na região Amazônica estudos abordando o lado das interaçôes sáo poucos e no caso de uso de componentes madeiráveis em consórcio os registros são mais escassos ainda.

A castanha-do-brasil e a cupiúba são espécies que ocorrem em toda a região Amazônica, abrangendo, no Brasil, os estados de Roraima, Rondônia, Acre, Amazonas, Pará e norte dos estados de Goiás e Mato Grosso, tendo como habitat preferido as matas de terra firme (Loureiro \& Silva,1968; Loureiro et al., 1979).

Ambas as espécies, fornecem madeira de boa qualidade, porém, o abate de árvores de castanheiras em florestas naturais, é proibido por lei, na medida em que servem de sustentaçâo e subsistência para as populaçóes que vivem à base do extrativismo (Fernandes \& Alencar, 1993), desempenhando papel fundamental na organizaçâo sócio econômica de grandes áreas extrativistas da floresta Amazônica (Silva, 2002). Desta forma, se torna opção natural para o reflorestamento de áreas alteradas em plantios puros ou sistemas consorciados.

Em geral, as castanheiras começam a frutificar aos oito anos de idade, atingindo aos doze anos a regularidade na produção. É uma espécie nativa de grande potencial para sistemas agroflorestais (SAFs) na Amazônia (Clement, 2000; Yared et al., 1993).

Dentro dos sistemas agroflorestais os benefícios estáo associados às combinaçóes entre os componentes e destes são ampliados para o sistema sendo melhor percebidos quanto aos efeitos microclimáticos, melhor ciclagem de nutrientes, maior biodiversidade e melhora nas características edáficas entre outros (Montagnini et al., 1992) .

Por ser o principal componente em sistemas agroflorestais, dentre as habilidades arbóreas é desejável que a espécie tenha a capacidade de produzir grande quantidade de biomassa com bom aporte de nutrientes, sendo esta, importante consideração a ser feita na escolha de espécies a serem utilizadas para a recuperação de áreas degradadas em locais pobres em nutrientes (Montagnini, 1997).

Segundo levantamento realizado por Wandelli \& Souza (2000); Cordeiro et al. (2004), a castanha-do-brasil é uma das espécies mais utilizadas em SAFs, o mesmo náo ocorrendo com a cupiúba sendo esta mais estudada em seu ambiente original. Mais recentemente, a combinação dessas duas espécies foi adotada em arranjo de sistema agroflorestal implantado em Roraima (Arco-Verde et al., 1999).
A cupiúba é espécie bastante utilizada em Roraima por madeireiros (Barbosa, 1990), não havendo programas de reposição e nenhum tipo de manejo e planejamento da área explorada.

Com grande potencial para investigaçóes na área médica, há indicaçôes de que a cupiúba também possa fornecer matéria-prima para as indústrias farmacêuticas, principalmente as que trabalham com substâncias químicas que inibam efeitos cancerígenos (Mesa-Siverio et al., 2003), agregando, assim maior valor de mercado à espécie.

O presente trabalho foi realizado com o objetivo de ajustar uma função de crescimento, obter uma função para estimar o diâmetro da copa e estudar o desempenho das espécies castanha-do-brasil (Bertholetia excelsa) e da cupiúba (Goupia glabra) a fim de que se possa estabelecer parâmetros silviculturais para plantio em sistema agroflorestal ou em plantios homogêneos.

\section{MATERIAL E MÉTODOS}

As mediçôes foram realizadas em um sistema agroflorestal implantado em 1995 no Campo Experimental Confiança da Embrapa Roraima, localizado a $90 \mathrm{~km}$ de Boa Vista no município do Cantá, Roraima. A região apresenta vegetação de floresta, clima do tipo Ami (Köppen), e precipitação variando entre 1795 - $2385 \mathrm{~mm}$. ano ${ }^{-1}$, com período chuvoso concentrado nos meses de maio a julho, que corresponde a mais de $55 \%$ do total de precipitação.

Como espécies componentes do sistema agroflorestal constam: Castanha-do-Brasil (Bertholetia excelsa), cupiúba (Goupia glabra), pupunha (Bactris gasipaes), cupuaçu (Theobroma grandiflorum); café (Coffea canephora); saman (Samanea saman); abiu (Micropholis venulosa); andiroba (Carapa guianensis) e Gliricidia (Gliricidia sepium) sendo esta última em bordadura.

O desenho espacial é do tipo multiestratificado, as parcelas medem $48 \mathrm{~m}$ x $48 \mathrm{~m}$ e o espaçamento entre espécies é de $2 \mathrm{~m} \times 3 \mathrm{~m}$, com área útil abrangendo $192 \mathrm{~m}^{2}$, contendo atualmente, os seguintes componentes: 2 plantas de andiroba (104 plantas/ha); 8 cupuaçus ( 416 plantas/ha); 6 pupunheiras (338 plantas/ha); 4 plantas de saman (208 plantas/ha); uma cupiúba ( 52 plantas/ha); uma castanha do Brasil ( 56 plantas/ ha); 6 plantas de café (312 plantas/ha) e 4 plantas de abiu (208 plantas/ha).

Na implantação dos sistemas agrosilviculturais, em 1995, a área foi gradeada recebendo calagem na dose de 2 t.ha $^{-1}$ (PRNT 100\%), aplicação de $40 \mathrm{~kg} \cdot \mathrm{ha}^{-1}$ de $\mathrm{P}_{2} \mathrm{O}_{5}$ e $50 \mathrm{~kg} \cdot \mathrm{ha}^{-1}$ de FTE BR 12.

Em outubro de 2005 foram medidas 121 árvores, sendo 71 castanheiras e 50 cupiúbas. Em todas as árvores foram medidos: a CAP (circunferência tomada a $1,30 \mathrm{~m}$ do solo) 
altura total, altura de inserçáo da copa, diâmetro da copa e ainda tomados dados qualitativos como qualidade do fuste, bifurcaçōes e ataques de fungos e insetos. A CAP foi medida com fita métrica; a altura total e de inserção da copa com o hipsômetro Blume-Leiss; o diâmetro da copa foi obtido através da medição de oito raios tomados em ângulos fixos, sendo o primeiro raio medido no sentido norte, seguindo no sentido horário de forma a permitir futuras remediçôes. Para a medição dos raios utilizou-se uma trena e uma vara de $2 \mathrm{~m}$. Os dados qualitativos foram obtidos avaliando a qualidade do fuste ( 1 - fuste reto sem defeitos que permite obter madeira de boa qualidade; 2 - fuste reto a levemente tortuoso com pequena excentricidade e presença de pequenos galhos que permite obter madeira de boa qualidade; 3 - fuste com tortuosidade acentuada, com defeitos e presença de galhos de porte regular; 4 - fuste inaproveitável, podre, oco, que não permite qualquer aproveitamento) e características como ( 1 - copa quebrada, 2 galhos quebrados, 3 -bifurcada abaixo de 1,30 m, 4- bifurcada acima de 1,30 m, 5 - envolta em cipós, 6 - morta, 7 - tronco quebrado, 8 - inclinada).

Para determinar equaçôes para estimar o diâmetro da copa em função do DAP, utilizou-se a análise de regressão, procedimento passo a passo (stepwise) onde as variáveis independentes (no caso, o Dap em sua forma original, quadrática, cúbica, inversa e logarítmica) foram selecionadas para $5 \%$ de probabilidade de confiança.

Para estimar o crescimento em diâmetro e altura em funçáo da idade, foram testados os modelos de Schumacher, Backman e Prodan, sendo utilizado como critério de seleção o coeficiente de determinação ajustado ( $\left.R^{2} a j\right)$, erro padrão de estimativa em porcentagem, Índice de Furnival e análise de distribuição dos resíduos. Para o controle de produçáo de frutos e sementes, todas as árvores de castanheira-do-brasil foram identificadas com placas numeradas, sendo tomados periodicamente informaçôes referentes ao número de frutos, peso do fruto, peso de sementes e número de sementes viáveis.

\section{RESULTADOS E DISCUSSÃO}

Os parâmetros quantitativos para as duas espécies podem ser observados na Tabela 1 .

Tabela 1 - Valores médios para sobrevivência em porcentagem (\%S), diâmetro a altura do peito (DAP), altura total (h), altura de inserção da copa (hic), diâmetro da copa (Dc), área basal individual (g), área basal por hectare (G) em SAF aos 10 anos de idade no Campo Experimental Confiança (Cantá-RR).

\begin{tabular}{lccccccc}
\hline ESPÉCIE & $\% S$ & $\begin{array}{c}\text { DAP } \\
(\mathrm{cm})\end{array}$ & $\begin{array}{c}\mathrm{h} \\
(\mathrm{m})\end{array}$ & $\begin{array}{c}\text { hic } \\
(\mathrm{m})\end{array}$ & $\begin{array}{c}\mathrm{Dc} \\
(\mathrm{m})\end{array}$ & $\begin{array}{c}\mathrm{g} \\
\left(\mathrm{m}^{2}\right)\end{array}$ & $\begin{array}{c}\mathrm{G} \\
\left(\mathrm{m}^{2} / \mathrm{ha}\right)\end{array}$ \\
\hline Castanheira & 98,6 & 25,5 & 14,0 & 3,3 & 9,2 & 0,052 & 2,66 \\
Cupiúba & 69,4 & 14,3 & 11,1 & 2,8 & 5,4 & 0,016 & 0,57 \\
\hline
\end{tabular}

O levantamento quantitativo indicou que $81,16 \%$ das árvores de castanha-do-brasil e 45\% das de cupiúba, apresentaram fuste reto sem defeitos que permite obter madeira de boa qualidade, com $18,64 \%$ e $52,5 \%$ apresentando fuste levemente tortuoso com galhos de pequeno diâmetro, respectivamente. Das árvores de cupiúba, 2,50\% apresentaram fuste com tortuosidade acentuada, com defeitos e galhos com diâmetro de porte regular.

Nos dois sistemas estudados as plantas apresentaram fuste com boas características comerciais.

Em relação a bifurcaçôes, $28,8 \%$ das árvores de castanhado-brasil não apresentaram bifurcaçôes, $6,8 \%$ apresentaram bifurcaçôes no primeiro terço, $35,6 \%$ no segundo e $28,8 \%$ no terceiro. Nas árvores de cupiúba $12,5 \%$ não apresentaram bifurcaçôes, $27,5 \%$ apresentaram no primeiro terço, $50 \%$ no segundo e $10 \%$ no terceiro.

O levantamento do estado fitossanitário indicou que das árvores de castanha-do-brasil, apenas 3,39\% se apresentaram em bom estado, sem evidências de ataques de fungos e insetos, 59,4\% apresentaram sintoma de mancha-das-folhas; $28,8 \%$ apresentaram mancha-das-folhas e ataques de insetos e 8,5\% ataque de insetos. Este resultado indica alta susceptibilidade da espécie ao ataque de fungos, uma vez que $88,2 \%$ dos indivíduos apresentavam ataques. Albuquerque (1960), classificou este patógeno como Cercospora bertholletia e não detectou prejuízos aparentes ao crescimento das árvores. Segundo Duarte (1999) embora a lesão ocorra em folhas maduras e não ocasione a queda prematura, a planta não chega a ser prejudicada no seu desenvolvimento e frutificação.

Soares et al., 2004, em estudos com SAFs localizados em áreas de produtores rurais, também não observaram problemas fitossanitários de importância, mas relataram ocorrer grandes diferenças na forma de crescimento das castanheiras na capoeira e no limpo (área com uso de tratos culturais), comentaram ainda, que a presença de capoeira contribuiu para a formação de fustes da melhor qualidade, menos bifurcaçōes ou outros defeitos.

Em Rondônia, em estudo realizado no Campo Experimental Machadinho D'Oeste foi relatado que a menor sobrevivência das castanheiras consorciadas pode ter sido decorrente de competiçáo por água com as demais plantas do sistema, principalmente a bananeira, espécie de crescimento mais rápido e distanciada apenas três metros das árvores de castanha-do-brasil (Vieira et al., 2002).

Nas árvores de cupiúba $45 \%$, apresentaram bom estado fitossanitário, $12,5 \%$ ataque por fungos causadores de mancha-das-folhas e $42,5 \%$ ataque de insetos.

A dimensão da copa é diretamente relacionada à capacidade fotossintética de uma árvore, sendo, portanto, um importante parâmetro em estudos de crescimento de árvores 
individuais, devido à alta correlação entre o tamanho da copa, o diâmetro do tronco (DAP) e a densidade (número de árvores). As equaçóes construídas para estimar o diâmetro da copa em função do DAP, com a utilização do procedimento passo a passo foram:

Castanha-do-brasil:

$$
\ln D c=2,81-14,386 \times(1 / D A P)(1) \mathrm{R}^{2}=0,87 \text { Syx } \%=9,76
$$

Cupiúba:

$\ln D c=0,541+0,00777 x D A P(2) \mathrm{R}^{2}=0,80 ;$ Syx $=10,07$

Com base nestas equaçôes se pode estimar o diâmetro da copa para as duas espécies, compará-las e fazer inferências sobre o espaço vital necessário para atingir uma determinada dimensão.

Na Tabela 2 foi observado que para um mesmo DAP, as duas espécies apresentam poucas diferenças em relação ao diâmetro da copa. Árvores de $20 \mathrm{~cm}$ de DAP (maior diâmetro observado para a cupiúba) apresentam mesmo diâmetro de copa estimado. Uma árvore de castanheira-do-brasil de $35 \mathrm{~cm}$ de diâmetro possui um diâmetro de copa estimado de $11 \mathrm{~m} \mathrm{e}$ uma área de copa de $95,03 \mathrm{~m}^{2}$. Esta informaçáo pode ser muito útil para a definição de espaçamentos em plantios e a definiçáo de espécies componentes em sistemas agroflorestais.

Tabela 2 - Diâmetro da copa estimado para as duas espécies estudadas aos 10 anos de idade.

\begin{tabular}{lcc}
\hline \multirow{2}{*}{ DAP $(\mathrm{cm})$} & \multicolumn{2}{c}{ Diâmetro da copa $(\mathrm{m})$} \\
\cline { 2 - 3 } & castanha-do-brasil & cupiúba \\
\hline 10 & 3,9 & 3,7 \\
15 & 6,4 & 5,6 \\
20 & 8,1 & 8,1 \\
25 & 9,3 & - \\
30 & 10,3 & - \\
35 & 11,0 & - \\
40 & 11,6 & - \\
\hline
\end{tabular}

A função de crescimento selecionada para estimar o crescimento em diâmetro e altura para as espécies estudadas foi a de Backman, que é expressa por:

$$
\ln y=b_{0}+b_{1} \ln t+b_{2} \ln ^{2} \mathrm{t}
$$

Onde: $\mathrm{y}$ = variável dependente (no caso diâmetro em $\mathrm{cm}$ e altura em m); $b_{0} ; b_{1}=$ coeficientes da funçấo; $t=$ idade (anos).

$\mathrm{O}$ ajuste desta função pode ser observado na Tabela 3 , e a curva cumulativa de crescimento para o DAP e a altura total nas Figuras 1 e 2.
Tabela 3 - Ajuste da função de Backman para estimar o diâmetro e a altura da castanha-do-brasil e cupiúba em função da idade.

\begin{tabular}{lccccc}
\hline \multicolumn{5}{c}{ Castanha-do-brasil } \\
\hline \multirow{2}{*}{$\begin{array}{l}\text { Variável } \\
\text { dependente }\end{array}$} & $\mathrm{b}_{0}$ & $\mathrm{~b}_{1}$ & $\mathrm{~b}_{2}$ & $\mathrm{R}^{2} \mathrm{aj}$ & $\mathrm{IF} \%$ \\
\hline $\mathrm{D}$ & 0,8372 & 0,6571 & 0,1905 & 0,70 & 8,5 \\
$\mathrm{H}$ & 0,6664 & 0,4793 & 0,1848 & 0,63 & 8,0 \\
\hline \multicolumn{5}{c}{ Cupiúba } \\
\hline Variável & \multicolumn{5}{c}{ Coeficientes } \\
dependente & $\mathrm{b}_{0}$ & $\mathrm{~b}_{1}$ & $\mathrm{~b}_{2}$ & $\mathrm{R}^{2} \mathrm{aj}$ & $\mathrm{IF} \%$ \\
\hline $\mathrm{D}$ & $-0,32168$ & 1,3646 & $-0,0194$ & 0,76 & 7,6 \\
$\mathrm{H}$ & $-0,6639$ & 1.8669 & -0.2302 & 0,63 & 6,3 \\
\hline
\end{tabular}
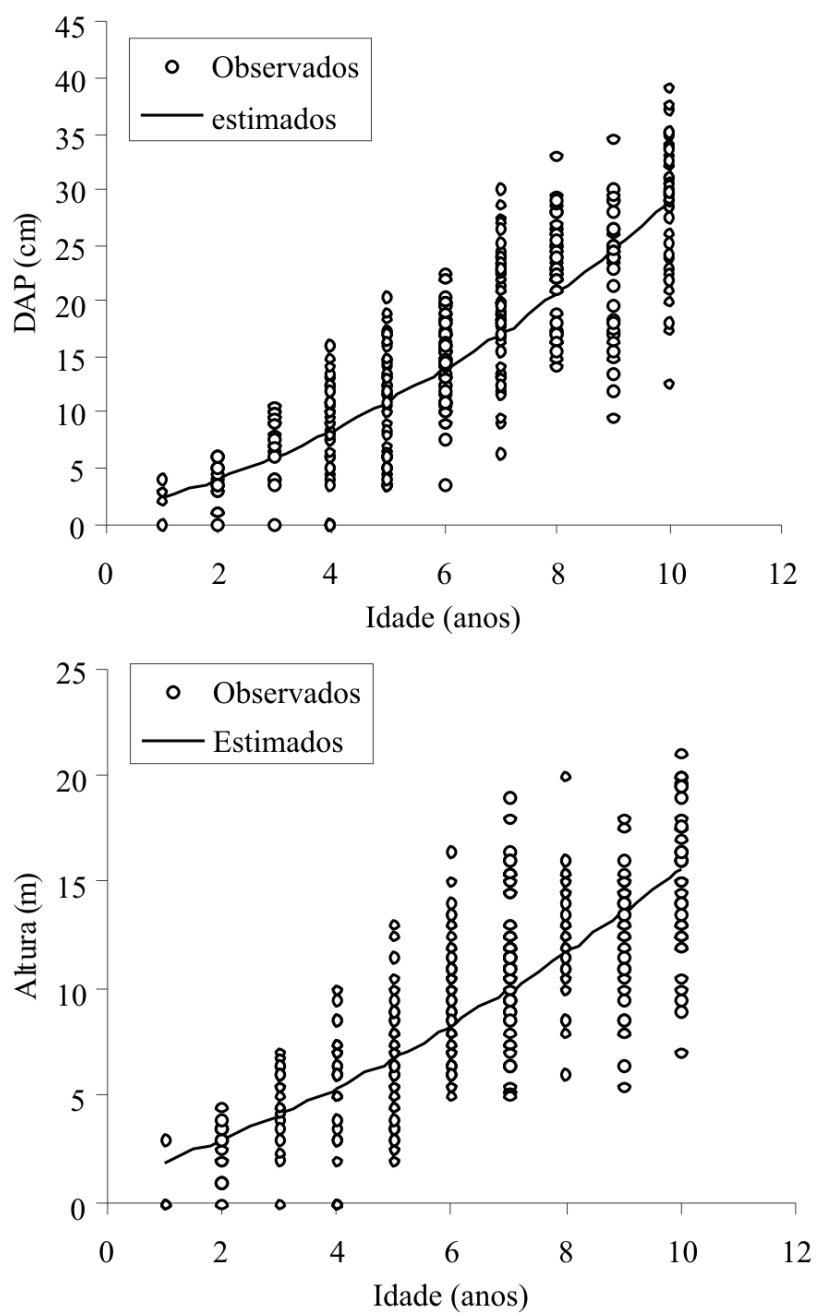

Figura 1 - Valores observados e estimados pela função de Backman para castanheira-do-brasil.

As estimativas de diâmetro e altura total podem ser observadas na Tabela 4 e a comparaçáo entre espécies na Figura 3. Foi observado o bom desempenho de ambas as espécies, onde, a castanha-do-brasil se destaca com incrementos médios anuais superiores a $2 \mathrm{~cm}$ em diâmetro e $1,4 \mathrm{~m}$ em altura total. 

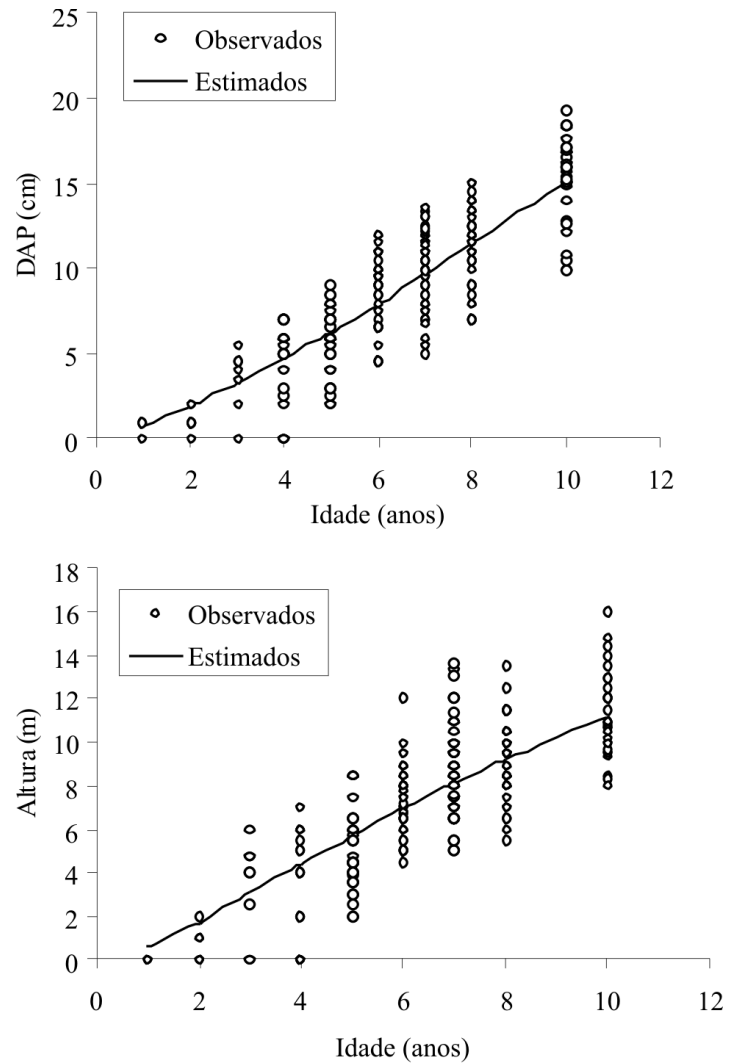

Figura 2 - Valores observados e estimados pela função de Backman para cupiúba.

Tabela 4 - Estimativas de crescimento para castanha-do-brasil e cupiúba em sistema agroflorestal aos 10 anos de idade.

\begin{tabular}{lcccc}
\hline Idade (anos) & DAP $(\mathrm{cm})$ & $\mathrm{h}(\mathrm{m})$ & IMAd & IMAh \\
\hline 1 & 2,3 & 1.95 & 2.3 & 1.95 \\
2 & 4,0 & 2.97 & 2.0 & 1.5 \\
3 & 6,0 & 4.12 & 2.0 & 1.4 \\
4 & 8,3 & 5.40 & 2.1 & 1.4 \\
5 & 10,9 & 6.80 & 2.2 & 1.4 \\
6 & 13.8 & 8.32 & 2.3 & 1.4 \\
7 & 17.1 & 9.96 & 2.4 & 1.4 \\
8 & 20.6 & 11.73 & 2.6 & 1.5 \\
9 & 24.6 & 13.62 & 2.7 & 1.5 \\
10 & 28.8 & 15.64 & 2.9 & 1.6 \\
\hline Idade (anos) & DAP (cm) & $\mathrm{h}(\mathrm{m})$ & $\mathrm{IMAd}$ & $\mathrm{IMAh}$ \\
\hline 1 & 0.7 & 0.51 & 0.7 & 0.51 \\
2 & 1.8 & 1.7 & 0.9 & 0.85 \\
3 & 3.2 & 3,0 & 1.1 & 1.0 \\
4 & 4.6 & 4.4 & 1.1 & 1.1 \\
5 & 6.2 & 5.7 & 1.2 & 1.1 \\
6 & 7.8 & 7 & 1.3 & 1.2 \\
7 & 9.6 & 8.1 & 1.4 & 1.1 \\
8 & 11.4 & 9.2 & 1.4 & 1.1 \\
9 & 13.2 & 10.2 & 1.5 & 1.1 \\
10 & 15.1 & 11.2 & 1.5 & 1.1 \\
\hline & & & &
\end{tabular}
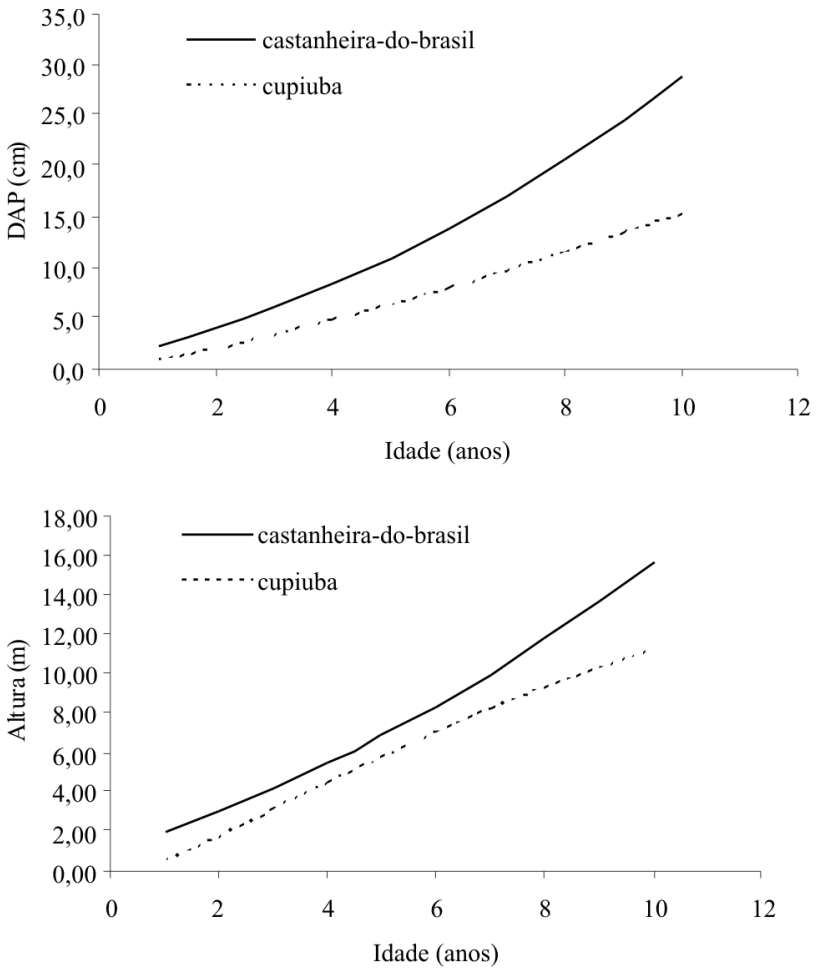

Figura 3 - Valores estimados para o DAP e a altura da castanha-do-brasil e cupiúba em função da idade.

Na Figura 3 é apontada a superioridade no crescimento para a castanha - do - brasil concordando com autores como Fernandes e Alencar (1993) e Yared et al., (1993) que a recomendam como excelente opção e uma das espécies nativas mais promissoras para o reflorestamento e recuperação de áreas degradadas na Amazônia.

No estudo de Vieira et al. (1998), a altura total média observada foi maior no cultivo consorciado em relaçáo ao monocultivo. Esta tendência foi mantida durante os treze anos de avaliação. Durante este período, o incremento médio anual (IMA) em altura total foi de 2,0 m no cultivo consorciado e $1,9 \mathrm{~m}$ no monocultivo. $\mathrm{O}$ diâmetro médio não foi influenciado pelo sistema de cultivo. Entretanto, até aos dez anos, o comportamento do DAP seguiu a mesma tendência da altura, maior no sistema consorciado em relação ao monocultivo .

Soares et al. (2004), registraram IMA do diâmetro de $3,1 \mathrm{~cm}$ no limpo (área com uso de tratos culturais) e de 1,8 $\mathrm{cm}$ na capoeira, enquanto o da altura foi de $1,6 \mathrm{~m}$ e $1,3 \mathrm{~m}$ respectivamente. Um indicativo de que a concorrência da capoeira atrasa o crescimento, enquanto força as árvores a crescer para cima, mudando a relação entre diâmetro e altura.

Aos 10 anos de idade, ambas as espécies apresentam crescimento linear (franco crescimento), sem tendência 
de reduçáo ou estagnaçáo. Este resultado indica que até o momento, tanto a castanheira quanto a cupiúba crescem livres de competiçáo, sem a necessidade de realização de desbastes.

Os maiores incrementos diamétricos observados em ambas as espécies a partir do quinto ano pode indicar uma melhora na qualidade do sitio, promovida pela ciclagem no sistema agroflorestal. Vieira et al. (2002), comentando o desempenho da castanheira em campo experimental em Rondônia, afirmam que o maior crescimento em altura total confirma uma interação positiva das demais plantas do sistema com a castanheira, possivelmente, decorrente de uma maior ciclagem de nutrientes, fundamentado em Quisen $e t$ al., (1996) que trabalhando nos mesmos sistemas verificaram que a quantidade de serrapilheira no cultivo consorciado foi 6,4 vezes maior que no monocultivo.

Em relação à castanha-do-brasil, Locatelli et al. (2002), ao avaliarem dados de plantios em diferentes espaçamentos e idades no estado de Rondônia, estimaram um diâmetro de $44,3 \mathrm{~cm}$ aos 220 meses (18 anos) e foi observada tendência a estabilização no crescimento em altura total após esta idade. Fernandes e Alencar (1993) observaram redução no incremento diamétrico a partir dos 6,5 anos em Manaus (AM).

Nos experimentos de Curuá-Una/PA, em plantios no espaçamento de $2,5 \times 2,4 \mathrm{~m}$, na idade 17 anos, a cupiúba apresentou valores de incremento médio anual em altura total de $0,854 \mathrm{~m}$ e em diâmetro de $0,861 \mathrm{~cm}$, para um incremento médio volumétrico de $16,245 \mathrm{~m}^{3} / \mathrm{ha} /$ ano (SUDAM, 1979).

\section{PRODUÇÃO DE FRUTOS 2005-2006.}

No ano de 2005, das 71 árvores avaliadas, 19 (26,4\%) se mostraram produtivas. Destas, apenas $3(11,1 \%)$ foram replantadas em 1998 estando atualmente com 7 anos. O número de frutos produzidos por estas árvores, variou de $2 \mathrm{a}$ 6 (média 3); o número de sementes de 9 a 37 (média 24) e o peso das sementes entre 150 e $770 \mathrm{~g}$ (média $572 \mathrm{~g}$ ). O reduzido número de plantas frutificando e a baixa produtividade está de acordo com Yared et al., (1993) ao afirmarem que em plantios, geralmente a castanha-do-brasil começa a frutificar aos 8 anos. Segundo o autor uma produção considerada normal é atingida a partir dos 12 anos.

Aos 10 anos o número de frutos produzidos por árvore variou de 1 a 33 (média 6/planta); o número de sementes variou de 10 a 532 (média 112/planta), com peso variando entre $75 \mathrm{~g}$ a $4 \mathrm{~kg}$ (média $750 \mathrm{~g} /$ planta). A relaçáo peso de sementes/peso dos frutos foi em média 0,302.

A relação número de sementes/ número de frutos e peso total de sementes por fruto foi de 18,9 e $157 \mathrm{~g}$ respectivamente. Estes valores são próximos aos observados por Macedo \&
Locatelli (2006), em plantio puro e sistema agroflorestal em Machadinho d Oeste (RO) com 18.6 e $160.6 \mathrm{~g}$.

A árvore mais produtiva com 33 frutos e 4 quilos de sementes apresentou as seguintes características: DAP $=28.6$ $\mathrm{cm}$; altura total $=16 \mathrm{~m}$, proporçáo de copa $=25 \%$, diâmetro da copa $=7.9 \mathrm{~m}$; e área da copa $=49.01 \mathrm{~m}^{2}$

\section{CONCLUSÕES}

A função de Backman foi selecionada para estimar o crescimento em diâmetro e altura total para a castanha-dobrasil e cupiúba.

Aos 10 anos de idade, tanto a castanha-do-brasil quanto a cupiúba crescem livres de competição no SAF, sem a necessidade de realização de desbastes.

As equaçóes escolhidas proporcionam uma boa estimativa do diâmetro da copa para as duas espécies, permitindonos vislumbrar o espaço vital necessário para atingir uma determinada dimensão

\section{BIBLIOGRAFIA CITADA}

Albuquerque, F.C. 1960. Mancha parda das folhas de castanheira do pará causada por uma nova espécie de fungo. Belém INSTITUTO AGRONÔMICO DO NORTE. 43p. (INSTITUTO AGRONÔMICO DO NORTE, Boletim Técnico, 38).

Arco Verde, M. F.; Gianluppi, D.; Schwengber, D. R.; Duarte, O. R.; Moreira, M.A B.; Medeiros, R.D.; Oliveira, J.M.F. de; Xaud, H.A.M. 1999. Desenvolvimento de Sistemas Agroflorestais para Recuperação de Áreas de Mata Abandonadas em Roraima. Programa Piloto para a Proteção das Florestas Tropicais do BrasilSubprograma de Ciência e Tecnologia - Resultados (Fase Emergencial e Fase 1), Ministério da Ciência e Tecnologia - Secretaria de Desenvolvimento Científico. Brasília, p. 289-308.

Barbosa, R. I. 1990. Análise do setor madeireiro do estado de Roraima. Acta amazonica, Manaus, v.20, n.9,p.193-209.

Clement, C.R. 2000. Biodiversidade Amazônica: exemplos e estratégias de utilização. 1. ed. Manaus: INPA, Programa de Desenvolvimento Empresarial e Tecnológico. p.119-131.

Cordeiro, I.M.C.C.; Gazel Filho, A. B. 2004. Espécies utilizadas em sistemas agroflorestais no Estado do Pará. In: Anais. Seção Técnica 1 - Espécies arbóreas de múltiplo uso - V Congresso Brasileiro de Sistemas Agroflorestais, SAFs: desenvolvimento com proteçáo ambiental 25 a 28 de outubro de 2004.

Duarte, M. de L.R. 1999. Doenças de plantas no trópico úmido brasileiro. I. Plantas Industriais. Belém: Embrapa Amazônia Oriental. 2996p.

Fernandes, N.P. \& Alencar, J. da C. 1993. Desenvolvimento de árvores nativas em ensaios de espécies. 4. Castanha-do-Brasil (Bertholletia excelsa H.B.K.), dez anos após o plantio. Acta Amazônica 23 (2-3): 191-198.

Locatelli, M.; Martins, E. P.; Vieira, A H.; Pequeno, P.L. de L.; Silva Filho, E.P. da; Ramalho, A R. 2002. Plantio de castanhado-brasil: uma opção para reflorestamento em Rondônia. Porto 
Velho: EMBRAPA: CPAF-RONDÔNIA. (Recomendaçóes Técnicas, 60).

Loureiro, A.A.; Silva, M.F. da; 1968. Catálogo de madeiras da Amazônia. Belém: SUDAM. v. 1.433 p.

Loureiro, A.A.; Silva, M.F. da; Alencar, J. da C.1979. Essências florestais madeireiras da Amazônia. Manaus. INPA. v. 1. 245p.

Macedo, R. de S.; Locatelli, M. 2006. Produção e biometria de frutos de castanha-do-Brasil (Bertholletia excelsa H.B.K) no municipio de Machadinho D'Oeste, Rondônia, Brasil. (www.unir.br/html/ pesquisa/Pibic_XIV). Acesso: 16/01/06.

Mesa-Siverio, D.; Estevez-Braun, A.; Ravello, A. G.; Murghia, J. R.; Rodriguez-Afonso, A. 2003. Novel DNA - Damaging tropolone derivatives from Goupia glabra. European Journal of Organic Chemistry, v. 21, p. $4243-4247$.

Montagnini, F. Jordan, C.F.; Matta Machado, R. 1997. Nutrient cycling and nutrient use efficiency in agroforestry systems. In: Ashton, M. \& Montagnini, F. (Eds.) The silvicultural basis for agroforestry systems, Winrock/Oxford \& IBH series in Agroforestry.

Montagnini. F. Y 18 colaboradores. 1992. Sistemas Agroforestalesprincipios y aplicaciones en los tropicos. $2^{\mathrm{a}}$. ed. Rev.y aum. - San José, C.R.: Organización para Estudios Tropicales. 622 p.

Quisen, R.C.; Souza, V.F. de; Castilla, C. 1996. Teste de sistemas agroflorestais para solo de baixa fertilidade - II Avaliação de biomassa de liteira sob o sistema. In: SIMPÓSIO INTERNACIONAL SOBRE ECOSSISTEMAS FLORESTAIS, 4., 1996, Belo Horizonte. Resumos... Belo Horizonte: Sociedade Brasileira para Valorização do Meio Ambiente. p 347 - 348.

Silva, F.A. 2002. Aplicação de microondas no processo de beneficiamento de castanha-do-brasil (Bertholetia excelsa). Campinas. Unicamp. Tese de Mestrado.

Soares, J. E. de C..; Van Leeuwen, J.; Gomes, J.B.M. 2004. O desenvolvimento da castanha-do-brasil (Bertholletia excelsa H.B.K.) em plantios agroflorestais no município de Manacapuru, Amazonas, Brasil In: Anais. Seçáo Técnica 1 - Espécies arbóreas de múltiplo uso - V Congresso Brasileiro de Sistemas Agroflorestais, safs: desenvolvimento com proteção ambiental. 25 a 28 de outubro de 2004, Curitiba, Paraná, Brasil, 1 CD-Rom.
SUDAM - Superintendência do Desenvolvimento da Amazônia. 1979b. Departamento de Recursos Naturais - Centro de Tecnologia Madeireira - Pesquisas e informação sobre espécies florestais da Amazônia, Belém, 1979b, 111p.

Vieira, A H.; Locatelli, M.; Souza, V.F. de 2002. Crescimento de castanha-do-brasil em dois sistemas de cultivo em solos de baixa fertilidade In: Anais. Seção Técnica 1 - Política e economia de SAFs - IV Congresso Brasileiro de Sistemas Agroflorestais, sistemas agroflorestais: tendência da agricultura ecológica nos trópicos: sustento da vida e sustento de vida. 21 a 26 de outubro de 2002, Ilhéus: Bahia, Brasil, CD-Rom.

Vieira, A.H.; Locatelli, M.; Souza, V.F. de. 1998. Crescimento de castanha-do-brasil em dois sistemas de cultivo. Porto Velho: EMBRAPA-CPAF Rondônia. p.12 (EMBRAPA-CPAF Rondônia Boletim de Pesquisa, 22)

Wandelli, E. V.; de Souza, M. do P. S. 2000. Análise da sustentabilidade de sistemas agroflorestais do Estado do Amazonas através de sua diversidade florística. In: Anais. Seção Técnica 1 - Biodiversidade e Processos Funcionais de SAF - III Congresso Brasileiro de Sistemas Agroflorestais, sistemas agroflorestais: manejando a biodiversidade e compondo a paisagem rural. 21 a 25 de novembro de 2000 , Manaus: Embrapa Amazônia Ocidental, 2000. p. 461 (Embrapa Amazônia Ocidental. Documentos, 7).

Yared, J.A.G.; Kanashiro, M.; Viana, L.M.; Castro, T.C. de; Pantoja, J.R.de S. 1993. Comportamento silvicultural de castanheira (Bertholletia excelsa H. \& K.), em diversos locais na Amazônia. In: CONGRESSO FLORESTAL PANAMERICANO, 1 1993, Curitiba-PR. Anais. Sociedade Brasileira de Silvicultura/ Sociedade Brasileira de Engenheiros Florestais, v.2 p.416-418.

Recebido em 04/08/2008

Aceito em 08/04/2009 
